\title{
Can posterior stand-alone expandable cages safely restore lumbar lordosis? A minimum 5-year follow-up study
}

\author{
Seung-Kook Kim ${ }^{1,2,3}$, Ogeil Mubarak Elbashier ${ }^{1}$, Su-chan Lee ${ }^{3}$ and Woo-Jin Choi ${ }^{4^{*}}$
}

\begin{abstract}
Background: Lumbar lordosis (LL) can be restored, and screw-related complications may be avoided with the stand-alone expandable cage method. However, the long-term spinopelvic changes and safety remain unknown. We aimed to elucidate the long-term radiologic outcomes and safety of this technique.

Methods: Data from patients who underwent multi-level stand-alone expandable cage fusion and 80 patients who underwent screw-assisted fusion between February 2007 and December 2012, with at least 5 years of follow-up, were retrospectively analyzed. Segmental angle and translation, short and whole LL, pelvic incidence, pelvic tilt, sacral slope (SS), sagittal vertical axis, thoracic kyphosis, and presence of subsidence, pseudoarthrosis, retropulsion, cage breakage, proximal junctional kyphosis (PJK), and screw malposition were assessed. The relationship between local, lumbar, and spinopelvic effects was investigated. The implant failure rate was considered a measure of procedure effectiveness and safety.
\end{abstract}

Results: In total, 69 cases were included in the stand-alone expandable cage group and 150 cases in the control group. The stand-alone group showed shorter operative time (58.48 \pm 11.10 vs $81.43 \pm 13.75, P=.00028)$, lower rate of PJK (10.1\% vs $22.5 \%, P=.03)$, and restoration of local angle (4.66 \pm 3.76 vs $2.03 \pm 1.16, P=.000079)$ than the control group. However, sagittal balance $(0.01 \pm 2.57$ vs $0.50 \pm 2.10, P=.07)$ was not restored, and weakness showed higher rate of subsidence $(16.31 \%$ vs $4.85 \%, P=.0018)$, pseudoarthrosis $(9.92 \%$ vs $2.42 \%, P=.02)$, cage, and retropulsion (3.55\% vs $0, P=.01$ ) than the control group.

Conclusions: Stand-alone expandable cage fusion can restore local lordosis; however, global sagittal balance was not restored. Furthermore, implant safety has not yet been proven.

Keywords: Lumbar lordosis, Proximal junctional kyphosis, Sacral slope, Sagittal imbalance, Stand-alone expandable cage fusion

\section{Background}

With the global aging society, degenerative lumbar spine disease is becoming a common health issue. Degenerative lumbar spine disease not only causes spinal stenosis but is also related to structural and functional problems.

\footnotetext{
*Correspondence: neurocwj@hanmail.net

${ }^{4}$ Department of Spine Center, Neurosurgery, Hurisarang Hospital, 618 Gyeryong-ro, Seo-gu, Daejeon 35299, Republic of South Korea

Full list of author information is available at the end of the article
}

One such problem, sagittal imbalance, is a crucial contributing factor to a decreased quality of life $[1,2]$.

Various approaches have been investigated to restore lumbar lordosis (LL) and sagittal balance. Direct decompression and fusion methods, including posterior lumbar interbody fusion and transforaminal lumbar interbody fusion, can achieve both canal decompression and solid fusion; nonetheless, the invasiveness into the bone and musculature is a drawback [3]. With the indirect

(c) The Author(s). 2020 Open Access This article is licensed under a Creative Commons Attribution 4.0 International License, which permits use, sharing, adaptation, distribution and reproduction in any medium or format, as long as you give appropriate credit to the original author(s) and the source, provide a link to the Creative Commons licence, and indicate if changes were made. The images or other third party material in this article are included in the article's Creative Commons licence, unless indicated otherwise in a credit line to the material. If material is not included in the article's Creative Commons licence and your intended use is not permitted by statutory regulation or exceeds the permitted use, you will need to obtain permission directly from the copyright holder. To view a copy of this licence, visit http://creativecommons.org/licenses/by/4.0/ The Creative Commons Public Domain Dedication waiver (http://creativecommons.org/publicdomain/zero/1.0/) applies to the data made available in this article, unless otherwise stated in a credit line to the data. 
decompression method, anterior lumbar interbody fusion [4] and lateral lumbar interbody fusion [5] can achieve a greater lordotic curve than that via the posterior approach; however, the possibility of incomplete decompression is a shortcoming.

Stand-alone expandable cages have been designed for restoring LL and correcting sacropelvic imbalance with simultaneous canal decompression, and these cages help avoid screw-related complications. Stand-alone cage showed efficacy in improving clinical symptom and a high fusion rate in a case series [6], and an expandable cage showed efficacy in restoring the sagittal balance in a retrospective analysis [7]. To the best of our knowledge, the long-term outcomes and safety of this procedure have not been established to date. Lumbar interbody fusion with screw fixation is the most common procedure for stabilization of spinal segment $[3,5]$, but it was not compared with a stand-alone technique. Thus, in this study, we hypothesized that if stand-alone expandable cages can restore and maintain sagittal balance safely; it can be an effective procedure. This study aimed to elucidate the long-term radiologic efficacy of this technique and evaluate its safety with implant issues.

\section{Methods}

\section{Study design and population}

This retrospective study reviewed prospective cohort medical data and radiographic findings of patients consecutively treated between February 2007 and December 2012 in a single spine institute. This study was conducted in accordance with the principles outlined in the Declaration of Helsinki and was approved by the institutional review board (Himchan IRB 169684-01-201906-04); furthermore, written informed consent was obtained from all patients. This manuscript adheres to the STROBE recommendations for reporting observational studies.

The study population selection is shown in Fig. 1 . The minimum sample size was calculated using Gpower for Windows software (version 3.1.9.4; Brunsbüttel, Germany). Because the safety and efficacy of single-level sagittal restoration is controversial [8] and proximal junctional kyphosis (PJK) shows different sagittal and spinopelvic profiles [9], these conditions were excluded. Among 1088 cases of fusion surgery, the following inclusion criteria were applied: (1) degenerative lumbar disease symptoms present for $>2$ months, (2) spinal instability confirmed on dynamic radiography but spondylolisthesis grade I or II only, and (3) involvement of at least two spinal levels. The exclusion criteria were (1) other causes of deformity (e.g., adolescent idiopathic scoliosis, PJK), (2) presence of a tumor, (3) infection, or (4) trauma.

\section{Operative technique and in-hospital management}

In most cases, we applied a facet-preserving technique [10] to support interbody fusion. To preserve sagittal stability before a fixed interbody fusion, more than $50 \%$ of the facet was preserved. The surgery was performed after spinal or epidural anesthesia. After applying an aseptic operative field dressing with alcohol and betadine, spinal levels were checked with a c-arm before incisions were made. After a midline incision was made based on the operative level, both multifidus muscles were dissected with a monopolar coagulator. Laminectomy was performed with a high-speed air drill and Kerrison punches, and the lower half of the upper laminar, lower half of the spinous process, and upper half of the lower laminar were removed. The ligamentum flavum was removed after the bone and ligament junction were detached with curettes. After meticulous bleeding control in the disc space, total discectomy was performed with a knife, pituitary forceps, and shavers. Rotating types of $8-10^{\circ}$ expandable interbody cages were used (Varian $^{\mathrm{TM}}$, Medyssey Co., Jecheon, Korea) for cage implantation. After fluoroscopic confirmation with the carm, muscle, and skin were sutured layer by layer.

Patients had 3 days of bed rest, and radiography was performed on postoperative day (POD) 3 and POD 15 . Patients were fitted with a thoracolumbar sacral orthosis to be used as a brace for 2 months post-surgery.

In the control group, the same laminectomy and discectomy procedures were performed; subsequently, a polyetheretherketone cage was inserted bilaterally, and pedicular screws and lordotic curved rods were applied. Ambulation started on POD 1, and radiography was performed on POD 1 and POD 10. The control group was also fitted with a thoracolumbar sacral orthosis to be used as a brace for 2 months post-surgery.

After procedure, both groups were prescribed intravenous patient-controlled analgesia, acetaminophen, intermittent neuroleptics, and opioids. Blood test results were checked for inflammation on POD 3 and 7. Outpatient clinic follow-up was schedules after 2 weeks, 1 month, 6 months, and yearly.

\section{Radiographic assessment}

The radiographic variables used in this study are shown in Table 1. Segmental parameters, such as the segmental angle and translation, were checked [14] to evaluate the local effect (Fig. 1a). For the evaluation of LL, the short LL, and whole LL were checked [15]. The following spinopelvic parameters were evaluated: pelvic incidence (PI), pelvic tilt (PT), and sacral slope (SS) (Fig. 1b) [14]. Global sagittal balance was assessed based on sagittal 

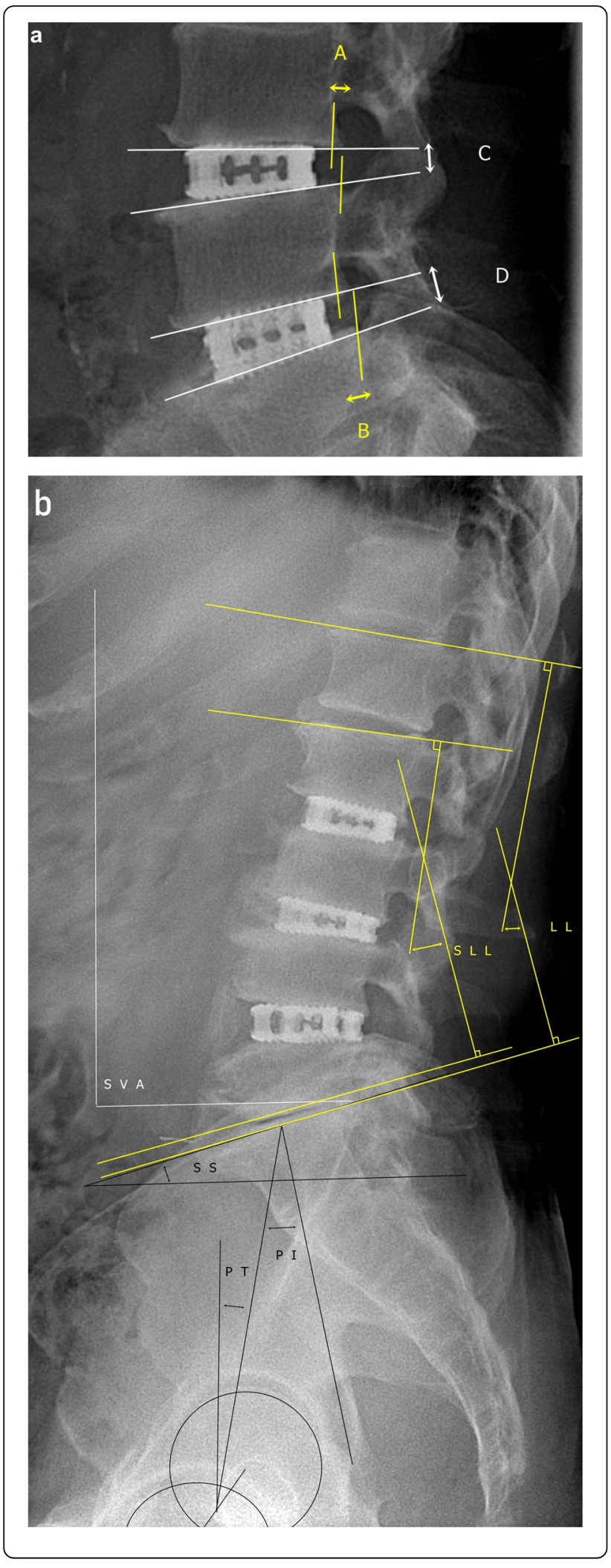

Fig. 1 Radiologic parameters. a Local factors. Translation is calculated as the mean of the diameters of translation (yellow characters). Segmental angle is calculated as the mean of the Cobb angles (white characters). b Lumbar factors. Lumbar lordosis (yellow characters) and spinopelvic profile (white characters). PI, pelvic incidence; PT, pelvic tilt; SLL, segmental lumbar lordosis; SS, sacral slope; SVA, sagittal vertical angle; WLL, whole lumbar lordosis

vertical balance, and thoracic kyphosis was assessed using a compensation mechanism [16]. Fusion rate and implant failures included subsidence [17], pseudoarthrosis, retropulsion, cage breakage, PJK, and screw malposition [18]. All variables were assessed after 1 year and at the final follow-up. All data were measured by three different observers (SKK, OME, and WJC) who had all worked as spinal physicians for more than 10 years.

\section{Statistical analysis and proficiency matching}

Statistical analyses were performed using $\mathrm{R}$ software for Windows version 3.6.1 ( $\mathrm{R}$ Foundation for Statistical Computing, Vienna, Austria). A $P$ value of less than .05 was considered statistically significant. Continuous variables (age, operative time, hospital stay, and all radiologically measured angles and lengths) were compared using the unpaired Student's $t$ test. Categorical variables (sex, operative type, and preoperative medical grade) were compared using the chi-square test. Proficiency matching between the segmental angle, LL, PI, and sagittal vertical balance was performed using the Pearson correlation analysis to identify whether positive correlation exists between local and global factors.

\section{Results}

\section{Baseline demographics}

The study population selection is described in Fig. 2. Of the 385 remaining cases after the application of the inclusion and exclusion criteria, single-level cases $(n=703)$, fusion for PJK cases $(n=18)$, and cases with short follow-up duration $(n=235)$ were excluded. The final patient group $(n=$ $149)$ was divided into an experimental group $(n=69)$ who received an expandable cage and a control group $(n=80)$.

Demographic data are summarized in Table 2. Age, sex, duration of symptoms, follow-up duration, and preoperative medical condition did not significantly differ between the two groups. The majority of surgeries performed involved two spinal levels, as opposed to three levels, in both groups (cage-alone, 95.66\%; control, 93.75\%; $P=.45$ ). The mean operative time was shorter in the cage-alone group than in the control group (58.48 min/level vs $81.43 \mathrm{~min} /$ level; $P=.00028)$. Hospital stay was longer in the cagealone group than in the control group (14.10 days vs 10.12 days; $P=.00001$ ). 
Table 1 Descriptions of the measurements and implant failure

\begin{tabular}{|c|c|c|}
\hline Category & Parameter & Definition \\
\hline \multirow[t]{2}{*}{ Local factor } & Segmental angle [11] & $\begin{array}{l}\text { Angle between the perpendicular line of the lower endplate of the upper vertebra } \\
\text { and upper endplate of the lower vertebra }\end{array}$ \\
\hline & Segmental translation [11] & Forward or backward slippage on a lateral radiograph \\
\hline \multirow[t]{2}{*}{ Lumbar factor } & Short lumbar lordosis [5] & $\begin{array}{l}\text { Cobb angle between the upper endplate of the fused vertebra and lower endplate } \\
\text { of the fused vertebra }\end{array}$ \\
\hline & Whole lumbar lordosis [5] & Cobb angle between the upper endplate of L1 and the lower endplate of L5 \\
\hline \multirow[t]{3}{*}{ Spinopelvic factor } & Pelvic incidence [12] & $\begin{array}{l}\text { Angle between the perpendicular line to the mid-point of the upper sacral endplate } \\
\text { and mid-point of both femoral heads }\end{array}$ \\
\hline & Pelvic tilt [12] & Angle between the vertical line from the femoral head and center of the sacral endplate \\
\hline & Sacral slope [12] & Angle between the vertical line and superior sacral endplate \\
\hline \multirow[t]{3}{*}{ Global sagittal balance } & Thoracic kyphosis [12] & Angle between the T4 upper endplate and T12 lower endplate \\
\hline & Sagittal vertical axis [12] & Distance from the vertical line of the $C 7$ body to the inferior lateral corner of the $L 5$ body \\
\hline & Sagittal balance [12] & Sagittal vertical axis line located within $5 \mathrm{~cm}$ \\
\hline \multirow[t]{4}{*}{ Implant failure } & Subsidence [13] & Greater or equal to $2 \mathrm{~mm}$ loss of height \\
\hline & Pseudoarthrosis [6] & Bony non-union between two vertebrae \\
\hline & Proximal junctional kyphosis [6] & Proximal junction Cobb angle of at least $10^{\circ}$ greater than the preoperative angle \\
\hline & Screw malposition [6] & Perforated pedicular screw \\
\hline
\end{tabular}

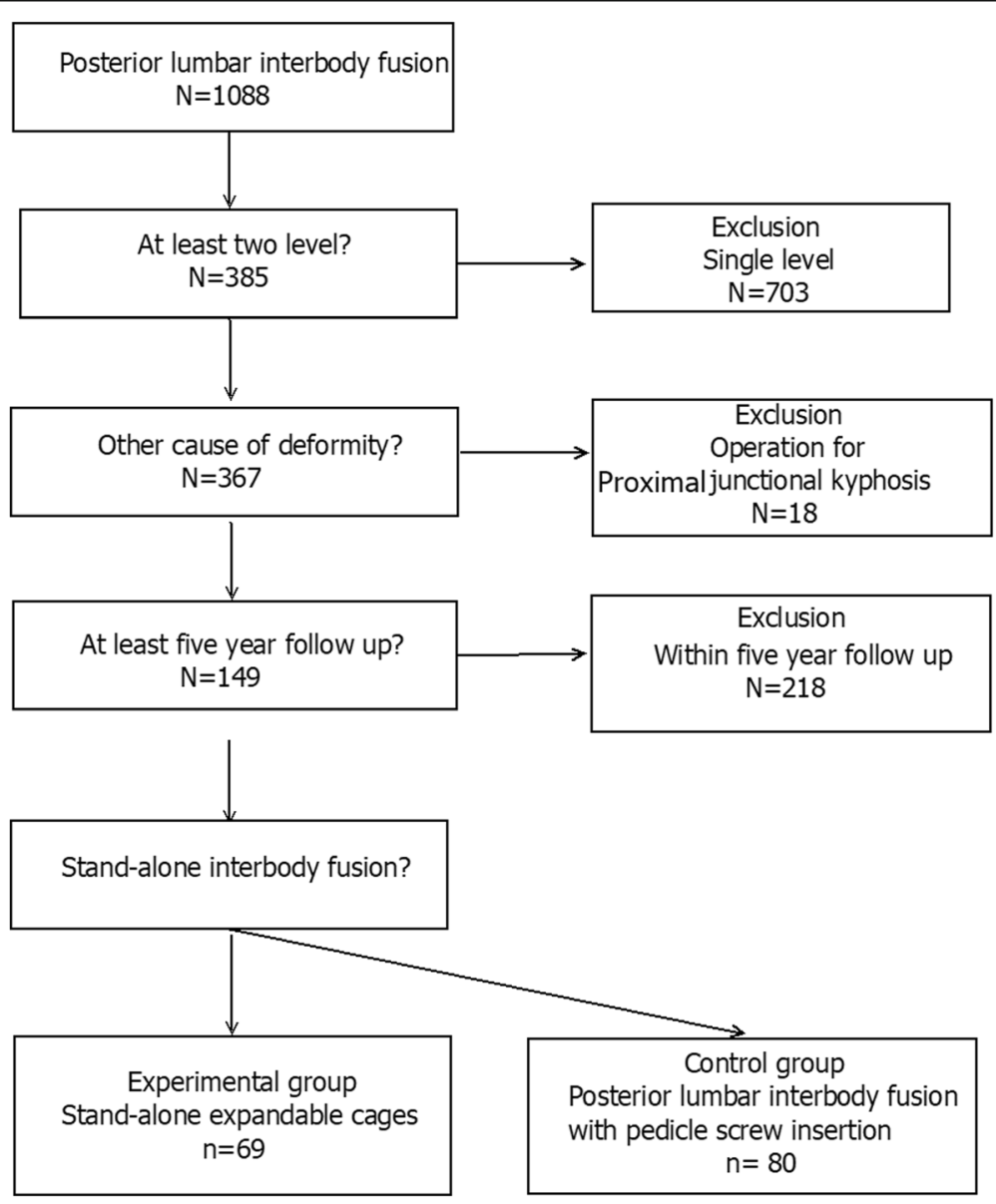

Fig. 2 Study population selection 
Table 2 Baseline characteristics of participants

\begin{tabular}{|c|c|c|c|c|}
\hline Factor & $\begin{array}{l}\text { Total } \\
(\boldsymbol{n}=149)\end{array}$ & $\begin{array}{l}\text { Stand-alone expandable cage fusion } \\
(\boldsymbol{n}=69)\end{array}$ & $\begin{array}{l}\text { Screw-assisted fusion } \\
(\boldsymbol{n}=80)\end{array}$ & $\boldsymbol{P}$ value \\
\hline Age (years), mean (SD) & $63.25(8.37)$ & $61.78(8.05)$ & $64.51(8.50)$ & $.15^{\mathrm{a}}$ \\
\hline Sex (\%) & & & & $.36^{\mathrm{b}}$ \\
\hline Male & $38(25.5)$ & M: 19 (27.54) & M: 19 (23.75) & \\
\hline Female & $111(74.5)$ & F: $50(72.46)$ & F: 61 (76.25) & \\
\hline Symptom duration (months), mean (SD) & $9.52(10.40)$ & $10.86(12.74)$ & $8.36(7.75)$ & $.14^{\mathrm{a}}$ \\
\hline Follow-up duration (months), mean (SD) & $72.91(17.53)$ & $75.23(14.23)$ & $70.91(11.62)$ & $.10^{\mathrm{a}}$ \\
\hline ASA-PS grade, \%, mean (SD) & & & & $.82^{\mathrm{b}}$ \\
\hline 1 & $13(8.72)$ & $4(10.14)$ & $6(75)$ & \\
\hline 2 & $144(87.92)$ & 67 (86.96) & $77(88.75)$ & \\
\hline 3 & $5(3.36)$ & $69(2.9)$ & $1(3.75)$ & \\
\hline No. of involved levels, \%, mean (SD) & & & & $.45^{\mathrm{b}}$ \\
\hline 2 & $141(94.63)$ & $66(95.65)$ & 75 (93.75) & \\
\hline 3 & $8(5.37)$ & $3(4.35)$ & $5(6.25)$ & \\
\hline Operative time/level, min, mean (SD) & $70.80(17.01)$ & $58.48(11.10)$ & $81.43(13.75)$ & $.00028^{\mathrm{a} *}$ \\
\hline Hospital stay, days, mean (SD) & $11.96(2.85)$ & $14.10(1.97)$ & $10.12(2.10)$ & $.00001^{\mathrm{a} *}$ \\
\hline
\end{tabular}

\section{Radiologic outcomes}

Evaluation of the preoperative, short-term, and final radiologic outcomes is summarized in Table 3 . With respect to the comparison of local and lumbar factors, the segmental angle was significantly corrected $(P=.000079$;
Fig. 3a). The segmental angle and short LL were greatly corrected as shown in the short-term results, and the correction angle decreased in both groups at the final follow-up. The segmental angle and LL showed a significant positive correlation in the Pearson correlation

Table 3 Comparison of the preoperative, 1 year, and final follow-up radiologic parameters in each group

\begin{tabular}{|c|c|c|c|c|c|c|c|c|c|}
\hline & \multicolumn{4}{|c|}{ Stand-alone expandable cage fusion $(\boldsymbol{n}=69)$} & \multicolumn{4}{|c|}{ Screw-assisted fusion $(\boldsymbol{n}=80)$} & \multirow[t]{2}{*}{$\boldsymbol{P}$ value } \\
\hline & Pre-op & 1 year & Final & $\Delta$ Parameter & Pre-op & 1 year & Final & $\Delta$ parameter & \\
\hline Segmental angle, degree, mean (SD) & $0.54(3.50)$ & $\begin{array}{l}5.17 \\
(2.39)\end{array}$ & $4.31(3.97)$ & $4.66(3.76)$ & $0.88(3.21)$ & $\begin{array}{l}5.35 \\
(1.98)\end{array}$ & $4.29(3.52)$ & $2.03(1.16)$ & $.000079^{a *}$ \\
\hline Translation, mm, mean (SD) & $3.62(1.88)$ & $\begin{array}{l}1.59 \\
(1.72)\end{array}$ & $1.60(1.37)$ & $2.02(1.57)$ & $3.05(1.59)$ & $\begin{array}{l}1.85 \\
(0.92)\end{array}$ & $0.95(1.10)$ & $1.66(1.39)$ & $.95^{\mathrm{a}}$ \\
\hline $\begin{array}{l}\text { Short lumbar lordosis, degree, mean } \\
\text { (SD) }\end{array}$ & $\begin{array}{l}14.03 \\
(10.17)\end{array}$ & $\begin{array}{l}17.41 \\
(10.45)\end{array}$ & $\begin{array}{l}16.76 \\
(12.74)\end{array}$ & $2.73(9.82)$ & $\begin{array}{l}16.66 \\
(12.87)\end{array}$ & $\begin{array}{l}17.80 \\
(10.55)\end{array}$ & $17.71(9.99)$ & $1.05(9.26)$ & $.28^{\mathrm{a}}$ \\
\hline $\begin{array}{l}\text { Whole lumbar lordosis, degree, mean } \\
\text { (SD) }\end{array}$ & $\begin{array}{l}28.50 \\
(16.17)\end{array}$ & $\begin{array}{l}28.79 \\
(15.13)\end{array}$ & $\begin{array}{l}29.02 \\
(17.04)\end{array}$ & $0.52(13.79)$ & $\begin{array}{l}31.43 \\
(16.94)\end{array}$ & $\begin{array}{l}32.45 \\
(14.51)\end{array}$ & $\begin{array}{l}33.40 \\
(14.62)\end{array}$ & $1.97(12.55)$ & $.50^{\mathrm{a}}$ \\
\hline Pelvic incidence, degree, mean (SD) & $\begin{array}{l}54.73 \\
(10.02)\end{array}$ & $\begin{array}{l}56.17 \\
(9.05)\end{array}$ & $55.44(9.08)$ & $\begin{array}{l}-0.68 \\
(11.21)\end{array}$ & $55.83(8.96)$ & $\begin{array}{l}56.47 \\
(10.40)\end{array}$ & $\begin{array}{l}55.97 \\
(10.26)\end{array}$ & $-0.13(8.08)$ & $.72^{a}$ \\
\hline Pelvic tilt, degree, mean (SD) & $\begin{array}{l}30.80 \\
(9370)\end{array}$ & $\begin{array}{l}45.47 \\
(12.75)\end{array}$ & $\begin{array}{l}29.50 \\
(10.41)\end{array}$ & $\begin{array}{l}-1.30 \\
(10.79)\end{array}$ & $28.04(9.34)$ & $\begin{array}{l}40.92 \\
(11.57)\end{array}$ & $27.20(9.16)$ & $-0.83(9.20)$ & $.77^{\mathrm{a}}$ \\
\hline Sacral slope, degree, mean (SD) & $24.01(8.20)$ & $\begin{array}{l}10.70 \\
(12.84)\end{array}$ & $28.84(8.00)$ & $4.48(14.24)$ & $28.04(8.73)$ & $\begin{array}{l}15.55 \\
(11.16)\end{array}$ & $28.84(8.75)$ & $\begin{array}{l}-1.51 \\
(13.58)\end{array}$ & $.0026^{\mathrm{a} *}$ \\
\hline Thoracic kyphosis, degree, mean (SD) & $4.69(3.69)$ & $\begin{array}{l}8.69 \\
(5.43)\end{array}$ & $7.99(3.89)$ & $3.29(2.18)$ & $4.53(3.26)$ & $\begin{array}{l}8.67 \\
(4.78)\end{array}$ & $8.24(3.71)$ & $3.70(2.64)$ & $.06^{\mathrm{a}}$ \\
\hline Sagittal vertical axis, cm, mean (SD) & $4.10(1.93)$ & $\begin{array}{l}4.13 \\
(1.87)\end{array}$ & $4.11(2.26)$ & $0.01(2.57)$ & $4.14(2.33)$ & $\begin{array}{l}4.41 \\
(1.88)\end{array}$ & $4.13(2.33)$ & $0.50(2.10)$ & $.07^{\mathrm{a}}$ \\
\hline
\end{tabular}

andependent Student's $t$ test

${ }^{*} \mathrm{P}<.05$

Pre-op preoperative, SD standard deviation 


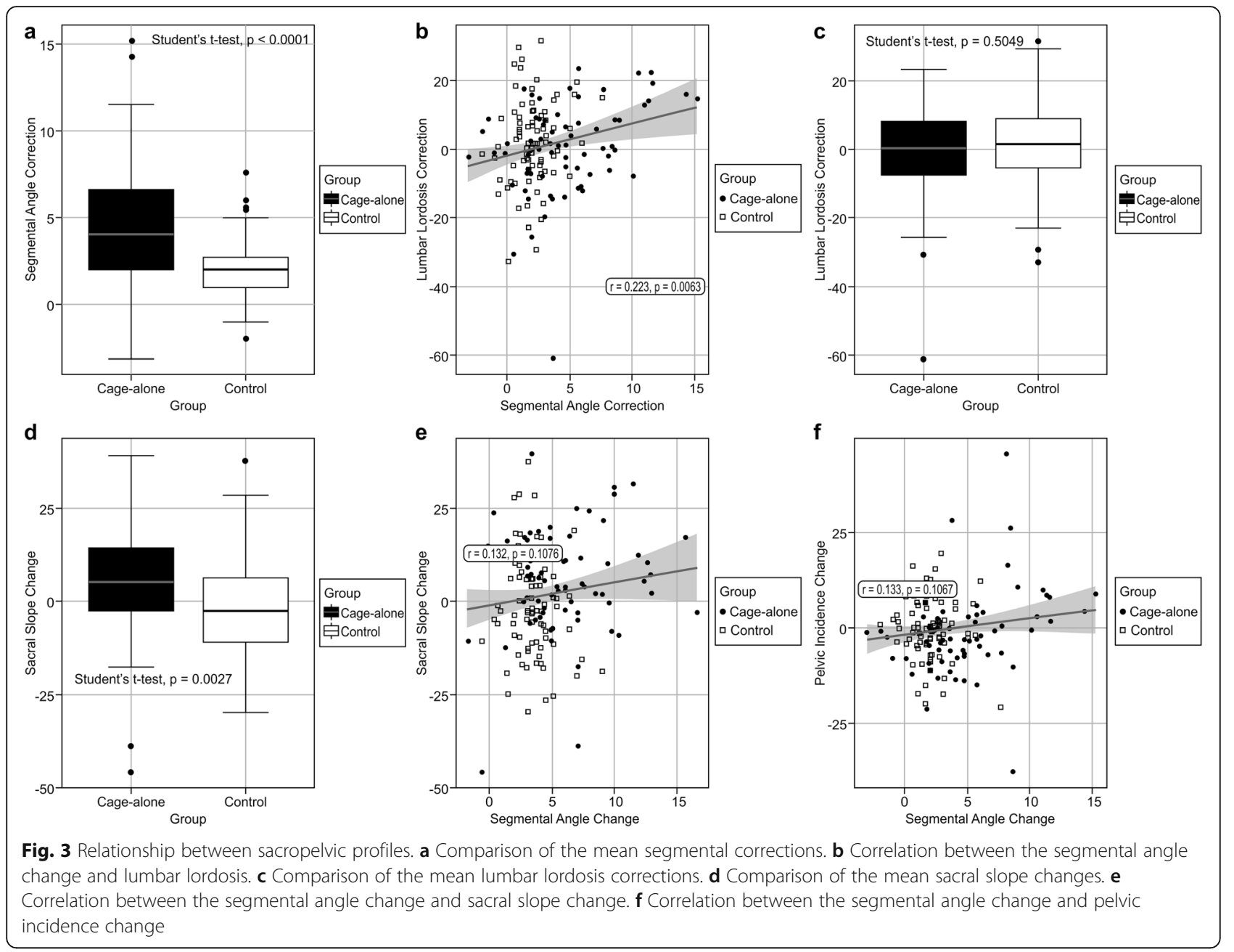

analysis (Fig. 3b) $(r=.223, P=.0063)$. However, this segmental lordosis correction did not restore LL $(P=.5049)$ (Fig. 3c). Even though SS significantly increased $(P=$ .0027) (Fig. 3d), PT decreased; as a result, PI was not significantly changed. Overall, global sagittal balance did not significantly change in either group.

SS also showed a positive correlation with segmental angle correction (Fig. 3e); however, this segmental angle correction did not show a significant positive correlation with PI (Fig. 3f).

\section{Fusion rate and implant failures}

The implant problems, including cage- and screwrelated complications, are summarized in Table 4. The control group showed a high fusion rate than the cagealone group, but it was not statistically significant (91.51\% vs $87.23, P=.22$ ). Subsidence (Fig. 4a), pseudoarthrosis (Fig. 4b), cage breakage (Fig. 4c), and retropulsion (Fig. 4) rates were significantly higher in the cage-alone group than in the control group $(P=.0018, P$ $=.02, P=.01$, and $P=.01$, respectively). However, the rates of $\mathrm{PJK}$ and screw malposition were significantly higher in the control group than in the cage-alone group $(P=.03$ and $P=.02$, respectively).

\section{Discussion}

To our knowledge, this study is the first to report the long-term outcomes of posterior stand-alone expandable cage fusion surgery. In this study, insertion of an expandable cage-alone not only increased the segmental angle but also correlated positively with LL. However, LL was not corrected, and the SS increased. High implant failure rates, weak support of the posterior element, and compensatory mechanisms are possible factors affecting these results. On the basis of our results, we have drafted a relationship chart of these factors (Fig. 5).

\section{Are there any advantages to the posterior stand-alone expandable cage approach?}

Screw placement at the pedicle has been regarded as the standard posterior stabilization procedure since 1969, and it was first introduced by Harrington and Tullos 
Table 4 Comparison of furoin rate and implant failure rate in each group

\begin{tabular}{|c|c|c|c|}
\hline Implant failure & Stand-alone expandable cage fusion ( $\boldsymbol{n}=141$ levels) & Screw-assisted fusion ( $\boldsymbol{n}=165$ levels) & $\boldsymbol{P}$ value \\
\hline Fusion rate, no. (\%) & $123(87.23)$ & $151(91.51)$ & $.22^{a}$ \\
\hline Subsidence, no. (\%) & $23(16.31)$ & $8(4.85)$ & $.0018^{a_{*}}$ \\
\hline Pseudoarthrosis, no. (\%) & $13(9.92)$ & $4(2.42)$ & $.02^{a *}$ \\
\hline Proximal junctional kyphosis, no. (\%, per cases) & $7(10.1)$ & $18(22.5)$ & $.03^{\mathrm{a} *}$ \\
\hline Cage breakage, no. (\%) & $8(5.67)$ & $0(0)$ & $.01^{a *}$ \\
\hline Cage retropulsion, no. (\%) & $5(3.55)$ & $0(0)$ & $.01^{a *}$ \\
\hline Screw malposition, no. (\%) & $0(0)$ & $6(3.63)$ & $.02^{a *}$ \\
\hline
\end{tabular}

[19]. The efficacy and superior support of this technique compared with other techniques, particularly the superior biomechanical strength [20] and presence of three columns, which provide more support than other techniques [21, 22], have been reported. However, this technique needs wide exposure for screw insertion and anatomic landmark confirmation. Furthermore, the reported rate of screw malposition ranges from 0 to $42 \%$ $[23,24]$. Because we skipped the process of screw placement in this study, the operative time was saved, the paraspinal and posterior facet complex was preserved with a small incision, and radiation exposure was reduced. Compared with the anterior lumbar interbody fusion and lateral lumbar interbody fusion procedures, simultaneous direct decompression can be performed and abdominal organs or hypogastric nerve injury can be avoided [12, 13]. In our result, both the cage-alone and screw fixation groups showed a decrease in the segmental angle in the long term, and expandable cages could achieve a greater angle. This shows that
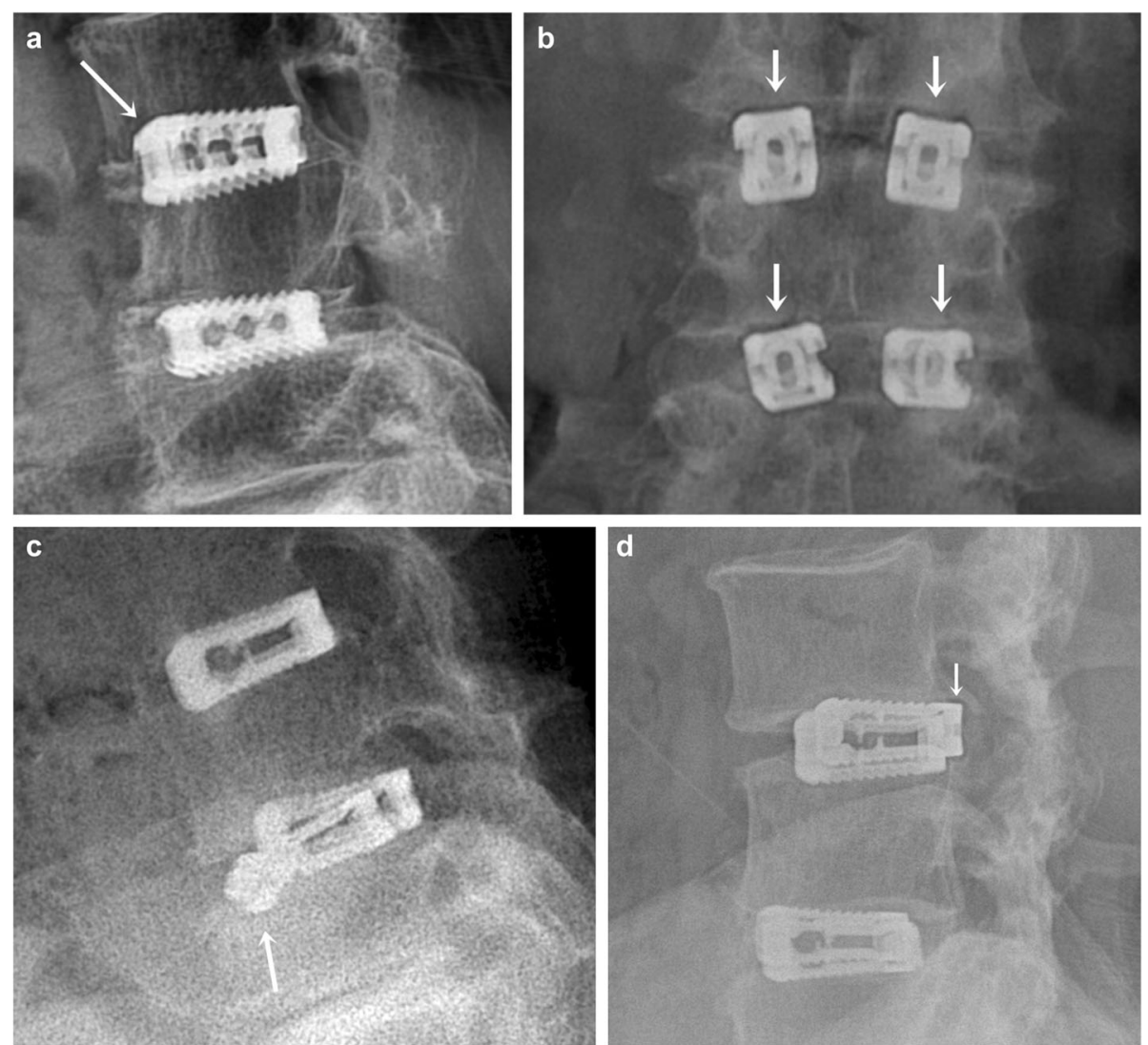

Fig. 4 Implant failures after follow-up. a Lateral radiograph showing subsidence. b Anterior-posterior radiograph showing pseudoarthrosis. c Lateral radiograph showing cage breakage. $\mathbf{d}$ Lateral radiograph showing retropulsion 


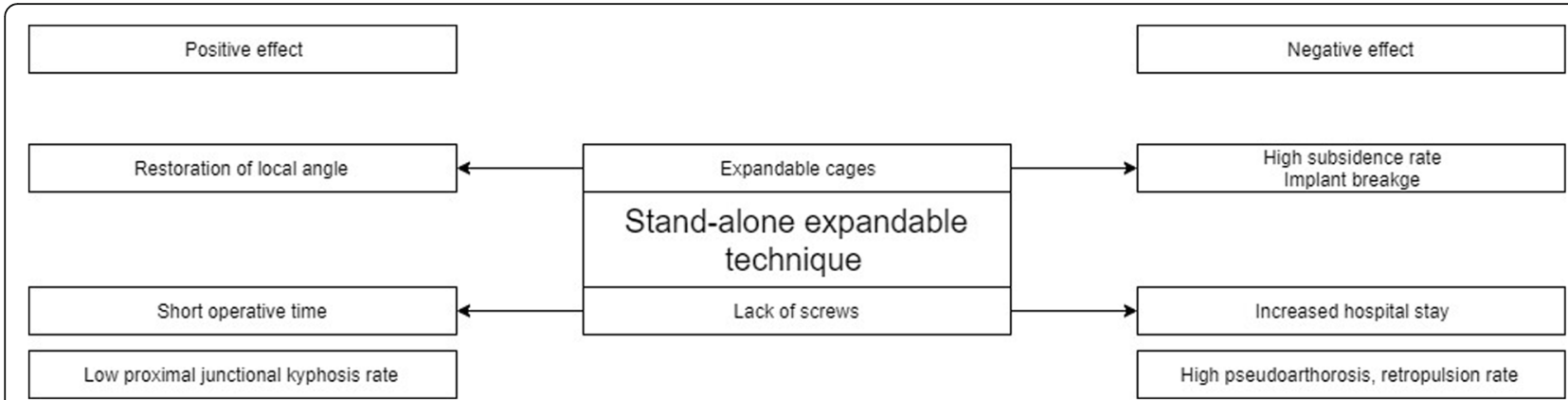

Fig. 5 Relationship map of the implant factors, patient factors, and sacropelvic profile

expandable cages have the effect of angle correction locally. In addition, we found that the rate of PJK was significantly lower in the cage-alone group than in the control group. As PJK is induced by overloading the junctional disc space [25], our facet-preserving technique might result in less overloading than the firmly fixed screw technique.

\section{Is interbody fusion without screw fixation safe?}

Compared with other fusion procedures, the possible complications of interbody fusion without screw fixation are totally different. In posterior fusion with a cage, owing to the wide exposure and screw placement, dural tear, rod fracture, PJK, and root damage are common complications [26]. With a stand-alone anterior or oblique approach, insufficient decompression means that additional decompression is required, and psoas muscle weakness and abdominal and vessel injuries [27] are common complications. In the short term, patients who received a posterior expandable cage-alone reported minor complications, such as posterior leg pain, infection, and wound problems [28]. However, long-term complications consisted of implant problems, especially subsidence, pseudoarthrosis, retropulsion, and cage breakage. High subsidence rate and breakage of cage can result from excessive restoration of the local angle [29]. Lack of screw did not maintain stability during the initial period, as shown by the high pseudoartrosis [30] and retropulsion rate. Even though our series showed that implant failure did not need replacement and revisions, it can be the cause of postoperative pain and disability during recovery.

\section{Why is it that an expandable cage cannot correct $L L$ and spinopelvic profile?}

The manufacturers have designed the expandable cages to be able to increase the lordosis by up to $9^{\circ}$; however, our measured mean segmental correction was only $4.66^{\circ}$. Subsidence [29] and pseudoarthrosis [30] are known factors that can reduce the lordotic angle. Cage breakage and retropulsion are possible debilitating events that can decrease LL. This may be the reason why the segmental angle did not correct LL, even though both parameters showed a significant positive relationship. Furthermore, weak posterior fixation can change the sacropelvic profile. In the normal aging process, PT and thoracic kyphosis increase. However, because PI is a consistent parameter [31], SS increases as a compensatory mechanism. However, our results in the cage-alone group were entirely different. Initially, the SS increased more in the cage-alone group than in the control group because of the lack of posterior support. Consequently, the PT was compensated for; hence, PI was preserved. Posterior screw fixation played a role in maintaining the SS in the control group, and the whole spinopelvic profile was better preserved in the control group than in the cagealone group.

\section{How to solve issues and gain better outcomes}

Three issues should be resolved to achieve better outcomes with this technique. First, we need to use more stable and advanced materials for interbody fusion. The use of enhanced titanium, additional bioactive glass ceramics, and other materials can reduce the rate of pseudoarthrosis [32]. Second, we need to preserve posterior support. Motion-preserving total disc replacement surgery showed more stable outcomes than the currently evaluated method [11] because of complete preservation of the posterior facet complex. Because this method also has a drawback (i.e., it is impossible to decompress the posterior canal), modified minimally invasive techniques, such as unilateral approaches, should be considered. Third, we need to increase bone density. The use of teriparatide in femoral fractures showed efficient prevention of bony subsidence [33]; thus, the use of hormones or medication may play a role in achieving better outcomes.

\section{Limitations of the study and future scope}

This study has limitations and several issues that need to be resolved in future studies. First, given the lack of blinding method and retrospective study design, many 
patients were lost to follow-up, and many confounding factors by indication are present. Even though we narrowed the indication in multilevel degenerative pathology, misclassification and selection bias can affect operation and follow-up. Second, there may have been major advancements in medications that support bone formation and advancements in the quality of cage materials since the patients in this study were treated. Therefore, it is essential for future studies to address the effects of better bone-forming agents and the application of stronger cage materials. Future studies should also have a multicenter prospective study design.

\section{Conclusions}

We reported the long-term outcomes of posterior expandable cage fusion surgery. The advantages of the procedure include the shorter operative time and low PJK rate. However, the longer hospital stay, higher rates of subsidence and pseudoarthrosis, and ineffective correction of the spinopelvic profile were disadvantages. Stand-alone expandable cage fusion can only restore local balance, but global sagittal balance was not restored. Furthermore, implant safety still has not been proven. This method still needs further investigation in today's current medical environment of advancements in cage materials and improved medications for bony support.

\section{Abbreviations \\ LL: Lumbar lordosis; PJK: Proximal junctional kyphosis; POD: Postoperative day; PI: Pelvic incidence; PT: Pelvic tilt; SS: Sacral slope}

\section{Acknowledgements \\ None}

\section{Authors' contributions}

SKK designed the study and performed all data analysis. WME drafted the manuscript. WJC carried out operation and radiologic evaluation. SCL carried out statistical analysis and supervised all process. All authors read and approved the final manuscript.

\section{Authors' information}

Woo-jin Choi MD, PhD, is consultant neurosurgeon in Korea. Seung-kook Kim $\mathrm{MD}$, PhD, is consultant spine surgeon in the United Arab Emirates and Korea. Ogeil Mubarak Elbashier, MD, is orthopedic senior specialist in the United Arab Emirates and Malaysia. Su-chan Lee is a consultant orthopedic surgeon in Korea.

\section{Funding}

The authors have not received grant support or research funding and do not have any proprietary interests in the materials described in the article.

\section{Availability of data and materials}

We attached all our raw data as a supplementary file.

\section{Ethics approval and consent to participate}

This study was conducted in accordance with the principles outlined in the Declaration of Helsinki and was approved by the institutional review board (Himchan IRB 169684-01-201906-04); furthermore, written informed consent was obtained from all patients.

\section{Consent for publication}

Not applicable.

\section{Competing interests}

The authors declare that they have no competing interests.

\section{Author details}

${ }^{1}$ Himchan and UHS Spine and Joint Centre, University Hospital Sharjah, Sharjah, United Arab Emirates. ${ }^{2}$ Department of Pharmaceutical Medicine and Regulatory Sciences, College of Medicine and Pharmacy, Yonsei University, Seoul, Republic of South Korea. ${ }^{3}$ Joint and Arthritis Research, Orthopaedic Surgery, Himchan Hospital, Seoul, Republic of South Korea. ${ }^{4}$ Department of Spine Center, Neurosurgery, Hurisarang Hospital, 618 Gyeryong-ro, Seo-gu, Daejeon 35299, Republic of South Korea.

Received: 4 May 2020 Accepted: 6 August 2020

Published online: 29 September 2020

\section{References}

1. Barrey C, Jund J, Noseda O, Roussouly P. Sagittal balance of the pelvis-spine complex and lumbar degenerative diseases. A comparative study about 85 cases. Eur Spine J. 2007;16:1459-67.

2. Jackson RP, McManus AC. Radiographic analysis of sagittal plane alignment and balance in standing volunteers and patients with low back pain matched for age, sex, and size. A prospective controlled clinical study. Spine (Phila Pa 1976). 1994;19:1611-8.

3. Kotwal S, Pumberger M, Hughes A, Girardi F. Degenerative scoliosis: a review. HSS J. 2011;7:257-64.

4. Pavlov PW, Meijers $\mathrm{H}$, van Limbeek J, Jacobs WCH, Lemmens JA, ObradovRajic M, et al. Good outcome and restoration of lordosis after anterior lumbar interbody fusion with additional posterior fixation. Spine (Phila Pa 1976). 2004;29:1893-9 discussion 1900.

5. Knight RQ, Schwaegler P, Hanscom D, Roh J. Direct lateral lumbar interbody fusion for degenerative conditions: early complication profile. J Spinal Disord Tech. 2009;22:34-7.

6. Neely WF, Fichtel F, Del Monaco DC, Block JE. Treatment of symptomatic lumbar disc degeneration with the VariLift-L interbody fusion system: retrospective review of 470 cases. Int J Spine Surg. 2016:10:15.

7. Kim JW, Park HC, Yoon SH, Oh SH, Roh SW, Rim DC. A multi-center clinical study of posterior lumbar interbody fusion with the expandable standalone cage (tyche ${ }^{\oplus}$ cage) for degenerative lumbar spinal disorders. J Korean Neurosurg Soc. 2007:42:251-7.

8. Kuhta M, Bošnjak K, Vengust R. Failure to maintain segmental lordosis during TLIF for one-level degenerative spondylolisthesis negatively affects clinical outcome 5 years postoperatively: a prospective cohort of 57 patients. Eur Spine J. 2019;28:745-50.

9. Kim JS, Phan K, Cheung ZB, Lee N, Vargas L, Arvind V, et al. Surgical, radiographic, and patient-related risk factors for proximal junctional kyphosis: a meta-analysis. Global Spine J. 2019;9:32-40.

10. Ray CD. Threaded titanium cages for lumbar interbody fusions. Spine (Phila Pa 1976). 1997;22:667-79.

11. Wuertinger C, Annes RDÀ, Hitzl W, Siepe CJ. Motion preservation following total lumbar disc replacement at the lumbosacral junction: a prospective long-term clinical and radiographic investigation. Spine J. 2018;18:72-80.

12. Boulay C, Tardieu C, Hecquet J, Benaim C, Mouilleseaux B, Marty C, et al. Sagittal alignment of spine and pelvis regulated by pelvic incidence: standard values and prediction of lordosis. Eur Spine J. 2006;15:415-22.

13. Kobayashi T, Atsuta Y, Matsuno T, Takeda N. A longitudinal study of congruent sagittal spinal alignment in an adult cohort. Spine (Phila Pa 1976). 2004;29:671-6.

14. Vialle R, Levassor N, Rillardon L, Templier A, Skalli W, Guigui P. Radiographic analysis of the sagittal alignment and balance of the spine in asymptomatic subjects. J Bone Joint Surg Am. 2005;87:260-7.

15. Baker JK, Reardon PR, Reardon MJ, Heggeness MH. Vascular injury in anterior lumbar surgery. Spine (Phila Pa 1976). 1993;18:2227-30.

16. Mehta VA, Amin A, Omeis I, Gokaslan ZL, Gottfried ON. Implications of spinopelvic alignment for the spine surgeon. Neurosurgery. 2015;70:707-21.

17. Macki M, Anand SK, Surapaneni A, Park P, Chang V. Subsidence rates after lateral lumbar interbody fusion: a systematic review. World Neurosurg. 2019; 122:599-606.

18. Bradford DS, Tay BK, Hu SS. Adult scoliosis: surgical indications, operative management, complications, and outcomes. Spine (Phila Pa 1976). 1999;24: $2617-29$. 
19. Harrington PR, Tullos HS. Reduction of severe spondylolisthesis in children South Med J. 1969;62:1-7.

20. An HS, Singh K, Vaccaro AR, Wang G, Yoshida H, Eck J, et al. Biomechanical evaluation of contemporary posterior spinal internal fixation configurations in an unstable burst-fracture calf spine model: special references of hook configurations and pedicle screws. Spine (Phila Pa 1976). 2004;29:257-62.

21. Kim YJ, Lenke LG, Cho SK, Bridwell KH, Sides B, Blanke K. Comparative analysis of pedicle screw versus hook instrumentation in posterior spinal fusion of adolescent idiopathic scoliosis. Spine (Phila Pa 1976). 2004;29: 2040-8.

22. Kim YJ, Lenke LG, Kim J, Bridwell KH, Cho SK, Cheh G, et al. Comparative analysis of pedicle screw versus hybrid instrumentation in posterior spinal fusion of adolescent idiopathic scoliosis. Spine (Phila Pa 1976). 2006;31:291-8.

23. Hicks JM, Singla A, Shen FH, Arlet V. Complications of pedicle screw fixation in scoliosis surgery: a systematic review. Spine (Phila Pa 1976). 2010:35:E465-E70.

24. Merloz P, Tonetti J, Pittet L, Coulomb M, Lavalleé S, Sautot P. Pedicle screw placement using image guided techniques. Clin Orthop Relat Res. 1998:39-48.

25. Glattes RC, Bridwell KH, Lenke LG, Kim YJ, Rinella A, Edwards C 2nd. Proximal junctional kyphosis in adult spinal deformity following long instrumented posterior spinal fusion: incidence, outcomes, and risk factor analysis. Spine (Phila Pa 1976). 2005;30:1643-9.

26. Zheng F, Cammisa FP Jr, Sandhu HS, Girardi FP, Khan SN. Factors predicting hospital stay, operative time, blood loss, and transfusion in patients undergoing revision posterior lumbar spine decompression, fusion, and segmental instrumentation. Spine (Phila Pa 1976). 2002;27:818-24.

27. Sofianos DA, Briseño MR, Abrams J, Patel AA. Complications of the lateral transpsoas approach for lumbar interbody arthrodesis: a case series and literature review. Clin Orthop Relat Res. 2012;470:1621-32.

28. Barrett-Tuck R, Del Monaco D, Block JE. One and two level posterior lumbar interbody fusion (PLIF) using an expandable, stand-alone, interbody fusion device: a VariLift ${ }^{\oplus}$ case series. J Spine Surg. 2017;3:9-15.

29. Schiffman M, Brau SA, Henderson R, Gimmestad G. Bilateral implantation of low-profile interbody fusion cages: subsidence, lordosis, and fusion analysis. Spine J. 2003;3:377-87.

30. Carpenter CT, Dietz JW, Leung KY, Hanscom DA, Wagner TA. Repair of a pseudarthrosis of the lumbar spine. A functional outcome study. J Bone Joint Surg Am. 1996;78:712-20.

31. Glassman SD, Bridwell K, Dimar JR, Horton W, Berven S, Schwab F. The impact of positive sagittal balance in adult spinal deformity. Spine (Phila Pa 1976). 2005;30:2024-9.

32. Lee JH, Kong CB, Yang JJ, Shim HJ, Koo KH, Kim J, et al. Comparison of fusion rate and clinical results between $\mathrm{CaO}-\mathrm{SiO} 2-\mathrm{P} 2 \mathrm{O} 5-\mathrm{B} 2 \mathrm{O} 3$ bioactive glass ceramics spacer with titanium cages in posterior lumbar interbody fusion. Spine J. 2016;16:1367-76.

33. Huang TW, Huang KC, Lin SJ, Chuang PY, Shih HN, Lee MS, et al. Effects of teriparatide on cementless bipolar hemiarthroplasty in patients with osteoporotic femoral neck fractures. BMC Musculoskelet Disord. 2016;17:300.

\section{Publisher's Note}

Springer Nature remains neutral with regard to jurisdictional claims in published maps and institutional affiliations.

Ready to submit your research? Choose BMC and benefit from:
- fast, convenient online submission
- thorough peer review by experienced researchers in your field
- rapid publication on acceptance
- support for research data, including large and complex data types
- gold Open Access which fosters wider collaboration and increased citations
- maximum visibility for your research: over 100M website views per year
At BMC, research is always in progress.
Learn more biomedcentral.com/submissions

